Revista de Metalurgia

Abril-Junio 2019, 55(2) e145

ISSN-L: 0034-8570

https://doi.org/10.3989/revmetalm.145

\title{
Estudio de la descomposición de fases durante el sinterizado por plasma de compósitos $\mathrm{Al}-5 \% \mathrm{Ni}_{3} \mathrm{Al}$
}

\author{
Norma V. De León-Murguía ${ }^{\mathrm{a} \otimes}$, Víctor M. López-Hirata ${ }^{\mathrm{a}}$, Carlos Ferreira-Palma ${ }^{\mathrm{a}}$, Diego I. Rivas- \\ López $^{\mathrm{a}}$, Felipe Hernández-Santiago ${ }^{\mathrm{b}}$, Héctor J. Dorantes-Rosales ${ }^{\mathrm{a}}$

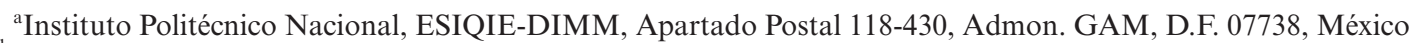 \\ bInstituto Politécnico Nacional, ESIME-AZC, Av. de las Granjas 682, Col. Santa Catarina, Azcapotzalco, México \\ ( $\bowtie$ Autor para la correspondencia: normav07@yahoo.com.mx)
}

Enviado: 29 Junio 2018; Aceptado: 5 Marzo 2019; Publicado on-Line: 21 Junio 2019

RESUMEN: La síntesis de compósitos base Al reforzados con partículas intermetálicas nanocristalinas de $\mathrm{Ni}_{3} \mathrm{Al}$ se llevó a cabo mediante la técnica de Spark plasma Sintering (SPS). La mezcla de polvos Al-5\% $\mathrm{Ni}_{3} \mathrm{Al}$ fue sinterizada por SPS a dos diferentes condiciones: (i) $450{ }^{\circ} \mathrm{C}, 47 \mathrm{MPa}$ y $180 \mathrm{~s}$ (4M47) y (ii) $520{ }^{\circ} \mathrm{C}, 16 \mathrm{MPa}$ y $600 \mathrm{~s}$ (5M16). Las partículas de $\mathrm{Ni}_{3} \mathrm{Al}$ fueron obtenidas mediante el proceso de aleado mecánico después de $1260 \mathrm{ks}$ de molienda. Los compósitos muestran una parcial descomposición en la intercara $\mathrm{Ni}_{3} \mathrm{Al}-\mathrm{Al}$, formando las fases $\mathrm{Al}_{3} \mathrm{Ni}$ y $\mathrm{Ni}_{2} \mathrm{Al}_{3}$. El análisis por MET confirman las características nanométricas del $\mathrm{Ni}_{3} \mathrm{Al}$ en los compositos Al- $5 \% \mathrm{Ni}_{3} \mathrm{Al}$. Los compósitos sinterizados $4 \mathrm{M} 47$ y $5 \mathrm{M} 16$ presentaron $95 \%$ y $87 \%$ de la densidad teórica y valores de microdureza Vickers de $62,3 \pm 7$ y 55,3 \pm 5 , respectivamente. Los ensayos de nanoindentación muestran que las propiedades mecánicas de los intermetálicos $\mathrm{Al}_{3} \mathrm{Ni}, \mathrm{Al}_{3} \mathrm{Ni}_{2}$ y Ni $3 \mathrm{Al}$, son mayores en condiciones de sinterizado a alta presión.

PALABRAS CLAVE: Aleado mecánico; Compósitos; Difusión; Interfase; Nanoindentación; Sinterizado por chispa de plasma

Citar como/Citation: De León-Murguía, N.V.; López-Hirata, V.M.; Ferreira-Palma, C.; Rivas-López, D.I.; HernándezSantiago, F.; Dorantes-Rosales, H.J. (2019). "Estudio de la descomposición de fases durante el sinterizado por plasma de compósitos Al-5\%Ni3Al”. Rev. Metal. 55(2): e145.https://doi.org/10.3989/revmetalm.145

ABSTRACT: Study of phase decomposition during spark plasma sintering of Al-5\% $\mathrm{Ni}_{3} \mathrm{Al}$ composites. The synthesis of Al-matrix composites reinforced with nanocrystalline intermetallic particles of $\mathrm{Ni}_{3} \mathrm{Al}$ was carried out with the Spark Plasma Sintering (SPS) technique. The Al-5\% $\mathrm{Ni}_{3} \mathrm{Al}$ powder mixture was sintered by SPS at two different conditions: (i) $450{ }^{\circ} \mathrm{C}, 47 \mathrm{MPa}$ and $180 \mathrm{~s}$ (4M47) and (ii) $520^{\circ} \mathrm{C}, 16 \mathrm{MPa}$ and $600 \mathrm{~s}(5 \mathrm{M} 16)$. The $\mathrm{Ni}_{3} \mathrm{Al}$ particles were obtained by mechanical alloying after a milling time of $1260 \mathrm{ks}$. The composites show partial decomposition on the $\mathrm{Ni}_{3} \mathrm{Al}-\mathrm{Al}$ interface, with the formation of the $\mathrm{Al}_{3} \mathrm{Ni}$ and $\mathrm{Ni}_{2} \mathrm{Al}_{3}$ phases. The analysis by TEM confirms the nanometric characteristics of the $\mathrm{Ni}_{3} \mathrm{Al}$ particles in the composites. The sintered composites $4 \mathrm{M} 47$ and $5 \mathrm{M} 16$ presented $95 \%$ and $87 \%$ of the theoretical density and Vickers microhardness values of $62.3 \pm 7$ and $55.3 \pm 5 \mathrm{HV}$ respectively. Nanoindentation tests show that the mechanical properties of the $\mathrm{Al}_{3} \mathrm{Ni}_{2} \mathrm{Al}_{3} \mathrm{Ni}_{2}$ and $\mathrm{Ni}_{3} \mathrm{Al}$ intermetallics are higher in high-pressure sintering conditions.

KEYWORDS: Composites; Diffusion; Interface; Mechanical alloying; Nanoindentation; Spark Plasma Sintering

ORCID ID: Norma V. De León-Murguía (https://orcid.org/0000-0003-2595-0582); Víctor M. López-Hirata (http:// orcid.org/0000-0002-7781-3419); Carlos Ferreira-Palma (http://orcid.org/0000-0002-4433-1552); Diego I. Rivas-López (https://orcid.org/0000-0003-4591-719X); Felipe Hernández-Santiago (https://orcid.org/0000-0002-2965-4257); Héctor J. Dorantes-Rosales (https://orcid.org/0000-0001-6973-1766)

Copyright: (C) 2019 CSIC. Este es un artículo de acceso abierto distribuido bajo los términos de la licencia de uso y distribución Creative Commons Reconocimiento 4.0 Internacional (CC BY 4.0). 


\section{INTRODUCCIÓN}

Los compósitos de matriz de aluminio (AMCs) reforzados con partículas intermetálicas son materiales que cumplen ampliamente con las demandas de las industrias de automoción, aviación y aeroespacial ya que presentan de manera general baja densidad, alto módulo elástico, bajos coeficientes de expansión térmica y buena resistencia al desgaste (Muñoz-Morris et al., 2005; Xue et al., 2015; Sameezadeh et al., 2016). Particularmente los intermetálicos del sistema $\mathrm{Ni}-\mathrm{Al}$ poseen excelentes propiedades mecánicas, dentro de los cuales destaca la fase $\mathrm{Ni}_{3} \mathrm{Al}$, con estructura cristalográfica del tipo L12, que presenta alto punto de fusión, alta dureza, baja densidad y buena resistencia a la corrosión y oxidación a elevadas temperaturas (Cao et al., 2007; Antolak-Dudka et al., 2013). Además, la presencia de partículas de $\mathrm{Ni}_{3} \mathrm{Al}$ mejora la resistencia al desgaste en aleaciones de aluminio y en aluminio puro (Díaz et al., 1996; Wang et al., 2001). Respecto al proceso de síntesis, el aleado mecánico es un método de estado sólido que permite la producción de polvos metálicos compuestos con características nanométricas. La reducción de tamaño de cristal a rango nanométrico mejora la ductilidad y aumenta la dureza de los polvos (Enayati et al., 2004; Yu et al., 2010).

La ruta pulvimetalúrgica ha sido exitosa en la síntesis de los AMCs donde partículas reforzantes de $\mathrm{Ni}_{3} \mathrm{Al}$ con una estructura nanométrica son integradas a la matriz de $\mathrm{Al}$ y se dispersan uniformente en ella a través de un proceso de mezclado (Abbasi et al., 2010; Hernández et al., 2014). Esta mezcla de polvos $\mathrm{Al} / \mathrm{Ni}_{3} \mathrm{Al}$ puede ser sinterizada por diferentes técnicas: sinterizado convencional $\left(\mathrm{O}^{\prime}\right.$ Donell y Looney, 2001), onda de choque (Hernández et al., 2014) prensado isostático en caliente (AntolakDudka et al., 2013), etc. Sin embargo, durante esta etapa es casi inevitable que ocurra crecimiento de grano debido al tiempo de permanencia, lo cual afecta las propiedades finales del producto terminado.

Un método que ha recibido mucha atención recientemente es la sinterización por chispa de plasma (SPS) la cual permite sinterizar polvos nanométricos con una densificación casi total y poco crecimiento de grano (Hungría et al., 2009). Este proceso permite controlar tanto la composición como el crecimiento del grano a través del cuidadoso control de los parámetros de consolidación, particularmente la tasa de calentamiento, la temperatura de sinterización y el tiempo de permanencia. El SPS combina simultáneamente la aplicación de presión uniaxial y una corriente directa a través de los polvos en un dado de grafito. Esta aplicación de corriente produce el efecto Joule a través de los polvos alcanzando altas tasas de calentamiento $\left(1000{ }^{\circ} \mathrm{C} \cdot \mathrm{min}^{-1} \mathrm{o}\right.$ incluso mayores) permitiendo la completa densificación de los polvos en cortos periodos de tiempo (orden de minutos). Por su parte el uso de presión mecánica durante el sinterizado también contribuye a incrementar la densidad, eliminando la porosidad y mejorando la difusión (Munir et al., 2006; Torralba y Campos, 2014; Fang et al., 2015; Li et al., 2015).

Diversos autores (Lieblich et al., 1997; Torres et al., 2006; Sajjadi et al., 2011) han descrito la reacción entre las partículas reforzantes de $\mathrm{Ni}_{3} \mathrm{Al}$ y la matriz de aluminio durante la consolidación mediante la disolución de las partículas de $\mathrm{Ni}_{3} \mathrm{Al}$ en cuatro etapas: (1) nucleación y crecimiento de la fase $\mathrm{Al}_{3} \mathrm{Ni}$ envolviendo al núcleo de $\mathrm{Ni}_{3} \mathrm{Al}$, (2) a tiempos más largos las fase $\mathrm{Al}_{3} \mathrm{Ni}_{2}$ nuclea y crece entre en núcleo disuelto $\mathrm{Ni}_{3} \mathrm{Al}$ y la creciente capa de $\mathrm{Al}_{3} \mathrm{Ni}$ (3) $\mathrm{La}$ fase $\mathrm{Ni}_{3} \mathrm{Al}$ se ha disuelto completamente y la partícula está formada por un núcleo de $\mathrm{Al}_{3} \mathrm{Ni}_{2}$ rodeado de la creciente capa de $\mathrm{Al}_{3} \mathrm{Ni}$, (4) finalmente la fase $\mathrm{Al}_{3} \mathrm{Ni}_{2}$ se ha disuelto completamente y únicamente permanece la fase de equilibrio $\mathrm{Al}_{3} \mathrm{Ni}$. No obstante, no se encuentran reportes de los efectos de las condiciones de sinterizado sobre las propiedades mecánicas de estas fases (dureza, módulo elástico).

Las propiedades mecánicas de los compósitos de matriz de aluminio están fuertemente relacionadas con las propiedades de la interface matriz/refuerzo, sin embargo, el estudio de esta región se ve limitado por su estrecha dimensión lo cual es necesario utilizar técnicas que permitan evaluar las zonas de reacción cuyo espesor puede ser inferior a $1 \mu \mathrm{m}$ (Campo et al., 2005). Una prueba adecuada es la nanoindentación que consiste en penetrar una muestra en el rango de profundidad submicrométrico con una carga de resolución nanométrica usando un equipo de alta precisión, el cual registra la carga y el desplazamiento continuamente. La dureza, modulo elástico y rigidez pueden obtenerse del análisis de las curvas de carga-desplazamiento creadas (Mussert et al., 2002; Ureña et al., 2005; Meza et al., 2008). El objetivo de este trabajo es evaluar la influencia que tienen algunos de los parámetros de sinterización sobre las propiedades mecánicas de las fases intermetálicas formadas en la intercara matriz-refuerzo de un compósito $\mathrm{Al}-5 \% \mathrm{vol} . \mathrm{Ni}_{3} \mathrm{Al}$ consolidado por SPS.

\section{MATERIALES Y MÉTODOS}

\subsection{Producción de las partículas de $\mathrm{Ni}_{3} \mathrm{Al}$ por aleado mecánico}

La síntesis de partículas nanoestructuradas de $\mathrm{Ni}_{3} \mathrm{Al}$ se llevó a cabo mediante el proceso de $\mathrm{AM}$ en un molino de bolas horizontal de polvos de aluminio y níquel de alta pureza $(99,98 \%)$ en la proporción estequiométrica Ni75Al25. Para el proceso se utilizó un molino de bolas bajo las siguientes condiciones: relación en de peso de 1:36 muestra/bolas, velocidad de 400 rpm, atmósfera de argón, bolas de molienda 
de acero inoxidable de $12,6 \mathrm{~mm}$ de diámetro y metanol como agente de control. Los tiempos de molienda fueron de 360, 720 y 1260 ks (Hernández et al., 2014). La mezcla de polvos de Al-5\%vol de $\mathrm{Ni}_{3} \mathrm{Al}$ se llevó a cabo mecánicamente en un molino tipo Spex sin carga de bolas durante 1,8 ks; con el propósito de lograr una condición de mezclado similar de las partículas de $\mathrm{Ni}_{3} \mathrm{Al}$ en el polvo de $\mathrm{Al}$ para las diferentes condiciones de consolidación.

\subsection{Consolidación de los polvos por Spark Plasma Sintering}

En esta técnica de sinterizado la mezcla de polvos son colocados en un dado de grafito y el punzón dentro de una cámara de vacío y entre los electrodos a través del cual se hace pasar un pulso de corriente directa y se aplica presión constante. El paso de corriente directa a través de las partículas de polvos genera un aumento instantáneo de temperatura $1000 \sim 2500{ }^{\circ} \mathrm{C}$ que produce la evaporación y fusión en la superficie de las partículas formando cuellos alrededor de las áreas de contacto (Saheb et al., 2012). Por su parte la aplicación de presión ayuda al flujo plástico del material permitiendo obtener materiales completamente densos en un corto tiempo de sinterizado. En este trabajo proponemos dos condiciones experimentales para obtener pastillas de $20 \mathrm{~mm}$ de diámetro con $5 \mathrm{~mm}$ de altura en un dado de grafito. La temperatura se estableció en base a las condiciones de deformación en caliente del aluminio $\left(\sim 0,7-0,8 \mathrm{~T}_{\mathrm{f}}\right)$, mientras que, la presión se determinó considerando las condiciones de carga máxima permitida por el dado. Todo ello con el propósito de estudiar su efecto en la microestructura y propiedades mecánicas de compósitos Al-5\%vol. $\mathrm{Ni}_{3} \mathrm{Al}$. La designación de las muestras y las condiciones de sinterizado se muestran en la (Tabla 1).

\subsection{Caracterización mecánica y microestructural}

Los compósitos obtenidos por SPS así como las partículas de $\mathrm{Ni}_{3} \mathrm{Al}$ obtenidas por $\mathrm{AM}$ fueron analizados por DRX con el propósito de identificar las fases presentes en las muestras. Se empleó un difractómetro marca Bruker modelo D8 Focus, con radiación de $\mathrm{Cu}-\mathrm{K} \alpha(\lambda=1.54060 \AA)$ y una velocidad de barrido de $2 \% \mathrm{~min}$. La distribución, morfología y composición de las partículas reforzantes de $\mathrm{Ni}_{3} \mathrm{Al}$

Tabla 1. Designación de los compósitos y sus condiciones de sinterizado

\begin{tabular}{llccc}
\hline Designación & Composición & $\begin{array}{c}\text { Temperatura } \\
\left({ }^{\circ} \mathbf{C}\right)\end{array}$ & $\begin{array}{c}\text { Presión } \\
(\mathbf{M P a})\end{array}$ & $\begin{array}{c}\text { Tiempo } \\
(\mathbf{s})\end{array}$ \\
\hline $4 \mathrm{M} 47$ & $\mathrm{Al}-5 \% \mathrm{Ni}_{3} \mathrm{Al}$ & 450 & 47 & 180 \\
$5 \mathrm{M} 16$ & $\mathrm{Al}-5 \% \mathrm{Ni}_{3} \mathrm{Al}$ & 520 & 16 & 600 \\
\hline
\end{tabular}

fueron analizadas mediante microscopia electrónica de barrido (MEB) usando un microscopio JEOL JSM 6701F equipado con un espectrómetro de energía dispersiva (EDS). A partir de las micrografías se determinó la fracción área de las fases y el tamaño de partícula empleando el software analizador de imágenes Sigma Scan Pro, que emplea un procedimiento sistemático de conteo puntual.

Los valores de densidad de las muestras consolidadas se determinaron usando el principio de Arquímedes. Se llevaron a cabo pruebas de microdureza Vickers a las muestras consolidadas aplicando cargas de 50 gf. La dureza $(\mathrm{H})$ y el módulo de Young (E) de las fases formadas en la intercara matriz-partícula ha sido determinada mediante la técnica de indentación instrumentada (nanoindentación) empleando un equipo Nanovea NHT (California, EUA), con un indentador de diamante tipo Berkovich y cargas máximas de $5 \mathrm{mN}$. Se realizaron 10 mediciones de cada fase identificada. El módulo de Young se calculó empleando el método de Oliver y Pharr (2004) considerando un coeficiente de Poisson de 0,3.

\section{RESULTADOS Y DISCUSIÓN}

\subsection{Síntesis de $\mathrm{Ni}_{3} \mathrm{Al}$ por $\mathrm{AM}$}

En la Fig. 1 se presenta la evolución de los difractogramas de RX de la mezcla de polvos Ni75Al25 durante 320, 760 y 1260 ks de aleado mecánico. La mezcla inicial presenta los picos característicos de la fase FCC rica en $\mathrm{Al}$ y la fase FCC rica en Ni. Después 360 ks $(100$ h) de molienda, se aprecia la reducción en intensidad de los picos de aluminio acompañado con un desplazamiento hacia bajos ángulos de los picos característicos del níquel. Estos fenómenos son indicativos de la formación de una solución sólida de $\mathrm{Ni}$ con átomos de $\mathrm{Al}$ en su red. Esto implica que, durante el proceso de molienda, los átomos de $\mathrm{Al}$ con un radio atómico mayor que el del $\mathrm{Ni}$ se han sido disueltos en la red del Ni formando una solución solida Ni(Al)ss. Posterior a 720 ks de molienda, se observa un ensanchamiento de los picos como resultado del refinamiento del tamaño del cristal y el aumento en la tensión interna producida por los impactos mecánicos (Suryanarayana y Norton, 1998). Un incremento en el tiempo de molienda, hacia los $1260 \mathrm{ks}$, provoca la completa transformación de la solución solida $\mathrm{Ni}(\mathrm{Al})$ ss en intermetálico $\mathrm{Ni}_{3} \mathrm{Al}$, con estructura desordenada debido a la ausencia de las reflexiones de ángulo bajo. La formación del intermetálico $\mathrm{Ni}_{3} \mathrm{Al}$ puede atribuirse a un largo tiempo de molienda $(350 \mathrm{~h})$ y se puede explicar a través de la difusión del $\mathrm{Ni}$ a causa de la acumulación de deformaciones internas y del refinamiento de grano asociado con la molienda prolongada. Estos resultados son acordes con lo observado por otros autores (Enayati et al., 2004; Yu et al., 


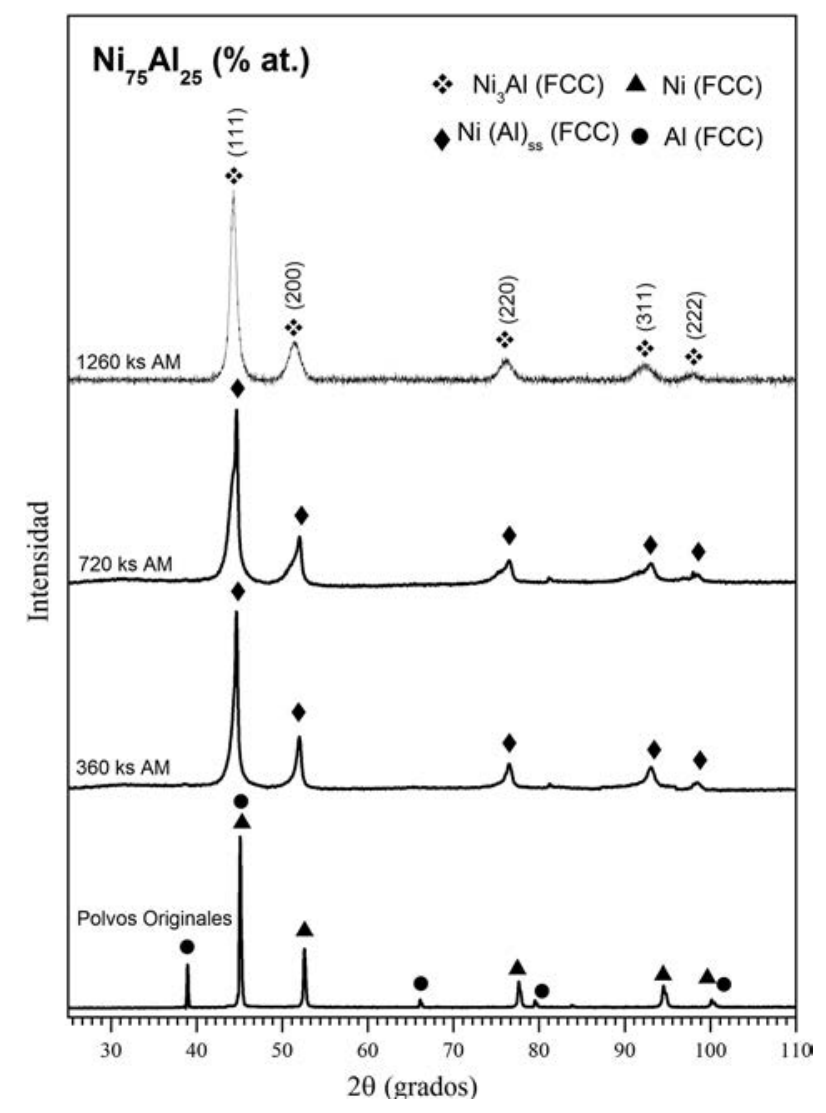

Figura 1. Difractograma de RX de la evolución del aleado mecánico de los polvos de Ni75-A125.

2010; Abbasi et al., 2010). Los patrones de XRD se analizaron utilizando el software de base de datos del centro internacional para datos de difracción: ICDD (2003). Mediante el uso de la ecuación de Scherrer y con base en las reflexiones de ángulo bajo del patrón de difracción se calculó el parámetro reticular y el tamaño de cristal para los diferentes tiempos de molienda. Estos resultados se resumen en la Tabla 2. Después de 1260 ks se obtuvieron partículas redondeadas de $\mathrm{Ni}_{3} \mathrm{Al}$ con un tamaño de aproximadamente $10 \pm 5 \mu \mathrm{m}$ como se observan en la Fig. 2 .

\subsection{Caracterización física de los compósitos $\mathrm{Al}-5 \% \mathrm{Ni}_{3} \mathrm{Al}$}

La Tabla 3 muestra los valores de densidad relativa y dureza Vickers de los compósitos 4M47 y 5M16. La densidad del compósito 4M47 es de $95 \%$, mayor a la presentada por el compósito 5M16 $(87 \%)$. Esto se debe a las condiciones de consolidación: en general, el aumento de la temperatura de sinterización es bueno para la difusión atómica y, por lo tanto, mejora la capacidad de sinterización en fase sólida y disminuye la fracción de volumen de los poros. La presión de compactación permite un fuerte contacto entre partículas lo que propicia la
Tabla 2. Evolución del parámetro de red y del tamaño de cristal desde $\mathrm{Ni}(\mathrm{Al})_{\mathrm{SS}}$ hasta la formación del intermetálico $\mathrm{Ni}_{3} \mathrm{Al}$

\begin{tabular}{lcc}
\hline $\begin{array}{l}\text { Tiempo de } \\
\text { Molienda (ks) }\end{array}$ & $\begin{array}{c}\text { Parámetro de Red } \\
(\mathbf{n m})\end{array}$ & $\begin{array}{c}\text { Tamaño de Cristal } \\
(\mathbf{n m})\end{array}$ \\
\hline 360 & 3,5213 & 23,69 \\
720 & 3,5248 & 13,93 \\
1260 & 3,5812 & 10,32 \\
\hline
\end{tabular}

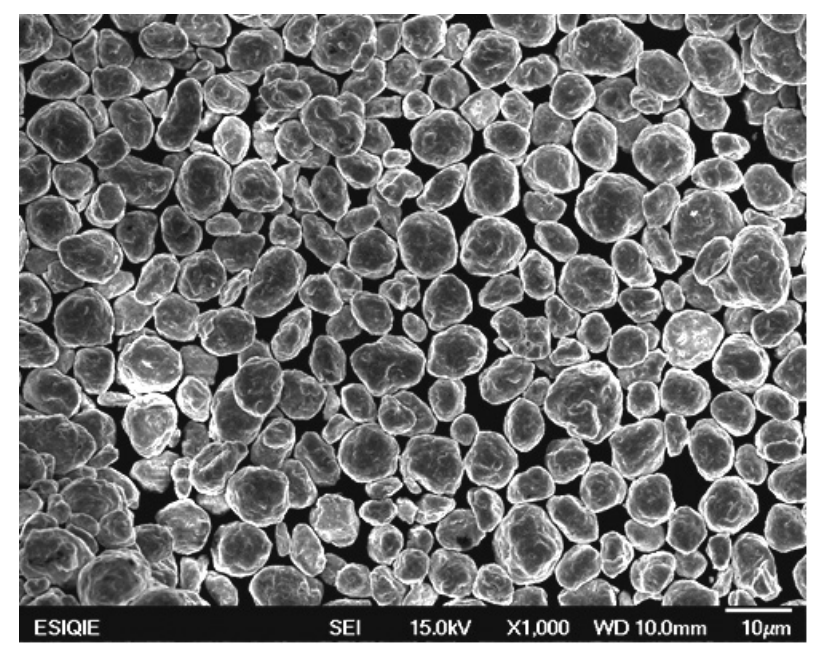

Figura 2. Morfología de los polvos de Ni-Al después de 1260 ks de AM.

Tabla 3. Densidad Relativa y Dureza de los compósitos $4 \mathrm{M} 47$ y $5 \mathrm{M} 16$

\begin{tabular}{lcc}
\hline Muestra & Densidad Relativa & Dureza $\left(\mathbf{H V}_{\mathbf{0 . 0 5}}\right)$ \\
\hline 4 M47 & 95 & $62,3 \pm 7$ \\
5 M16 & 87 & $55,3 \pm 5$ \\
\hline
\end{tabular}

difusión entre ellas. Por otra parte, la distribución y fracción de la fase reforzante son los factores determinantes en los resultados de microdureza.

En el caso del compósito 4M47, la mayor presión de compactación $47 \mathrm{MPa}$ permitió un fuerte contacto entre partículas y la temperatura de $450{ }^{\circ} \mathrm{C}$ fue suficiente para producir una fusión local en los límites de las partículas de $\mathrm{Al}$ reduciendo la porosidad por lo que se obtuvieron mayores valores de densidad y dureza. Los valores de densidad y dureza del compósito 5M16 fueron menores a pesar de la mayor temperatura $520^{\circ} \mathrm{C}$ y tiempo de permanencia bajo presión (600 s) utilizados en su consolidación. Estos factores no fueron suficientes para compensar la falta de unión entre partículas necesaria para aumentar la densidad. El proceso de mezclado mecánico permitió distribuir homogéneamente las partículas de $\mathrm{Ni}_{3} \mathrm{Al}$ en la matriz de aluminio lo que permitió incrementar significativamente la dureza 
de los compósitos en comparación con el aluminio puro, cuya dureza en condiciones similares de sinterizado (Saheb et al., 2015) se encuentra entre 326,3 y $369,3 \mathrm{MPa}$, lo cual equivale a una dureza Vickers entre 33,2 y 37,6 .

\subsection{Caracterización estructural y microestructural}

En la Fig. 3a se presenta difractograma de RX de la muestra 4M47, en el cual se identifican las reflexiones características del aluminio (PCPDWIN 04-0787) y la fase reforzante $\mathrm{Ni}_{3} \mathrm{Al}$ (PCPDWIN 09-0097). En la Fig. 3b se presenta una ampliación del rango $20-55^{\circ}$, en él se aprecian picos agudos a bajos ángulos que confirman la presencia de las fases intermetálicas $\mathrm{Al}_{3} \mathrm{Ni}$ (PCPDWIN 02-0416) y $\mathrm{Al}_{3} \mathrm{Ni}_{2}$ (PCPDWIN 14-0648). En la Fig. 4a se presenta el difractograma de DRX de la muestra 5M16, en el cual se identifican las reflexiones características del aluminio y una disminución en la intensidad de los picos correspondientes a la fase reforzante $\mathrm{Ni}_{3} \mathrm{Al}$ y las fases intermetálicas $\mathrm{Al}_{3} \mathrm{Ni}_{\mathrm{y}} \mathrm{Al}_{3} \mathrm{Ni}_{2}$, mostradas en la Fig. 4b. La menor intensidad en los picos de las fases intermetálicas $\mathrm{Al}_{3} \mathrm{Ni}$ y $\mathrm{Al}_{3} \mathrm{Ni}_{2}$ sugiere una menor fracción volumétrica de las mismas lo que implicaría un menor grado de descomposición de las partículas reforzantes originales.

En las Figs. 5a y 6a se muestran imágenes de MEB en modo de contraste composicional de la microestructura de los compósitos sinterizados en las condiciones 4M47 y 5M16 respectivamente. El compósito 4M47 presenta un menor grado de porosidad relacionado con la alta presión de compactación empleada, $47 \mathrm{MPa}$, la cual condujo a un aumento en el número de puntos de contacto entre las partículas de polvos de Al y las partículas (a)

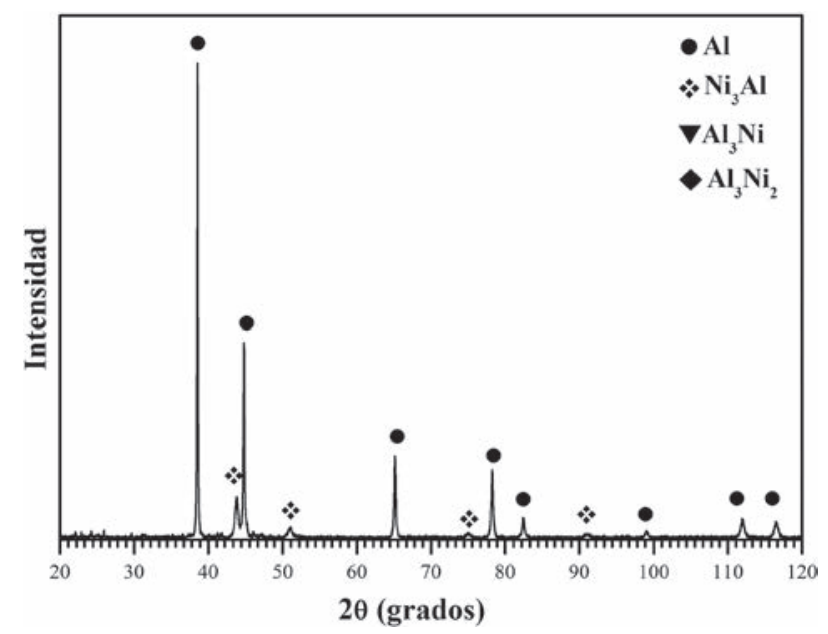

(b)

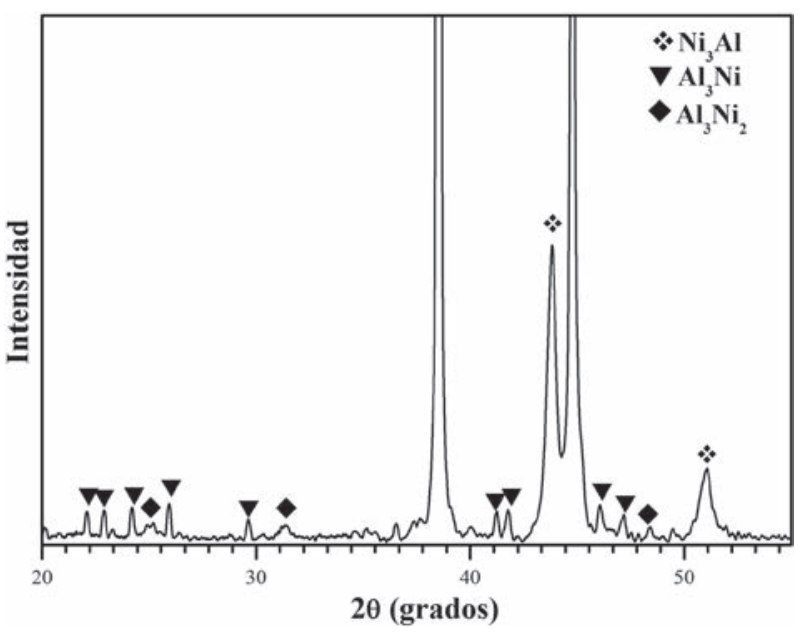

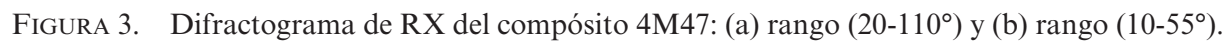

(a)

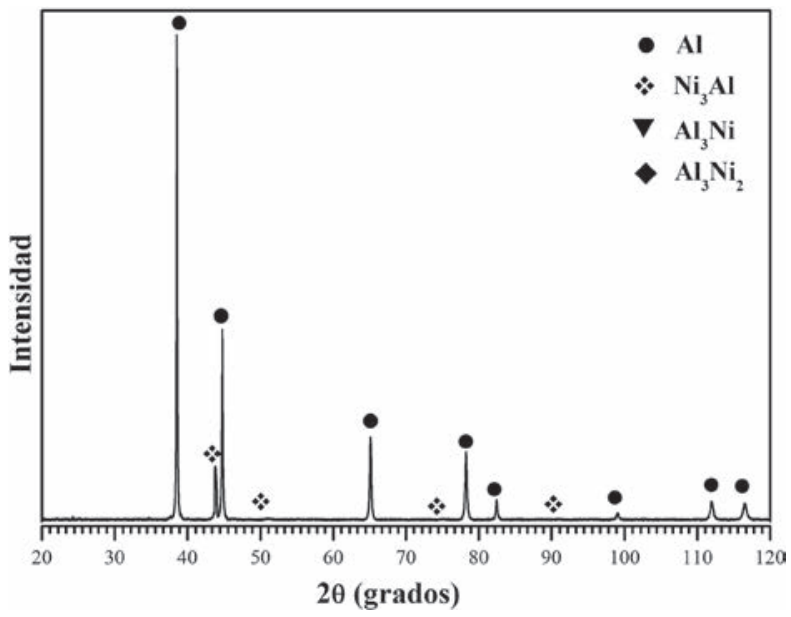

(b)

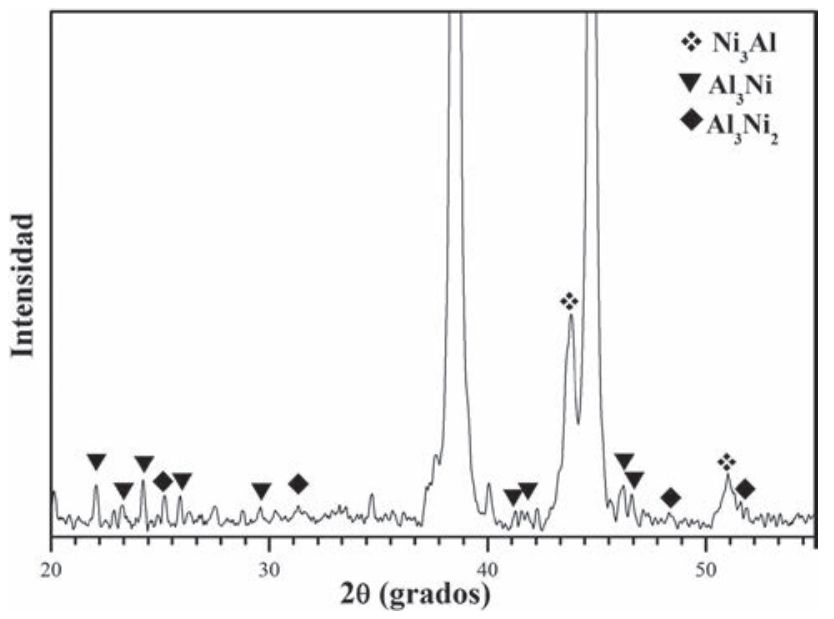

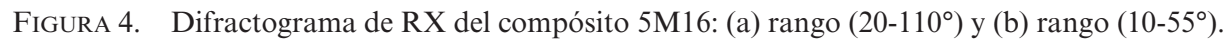



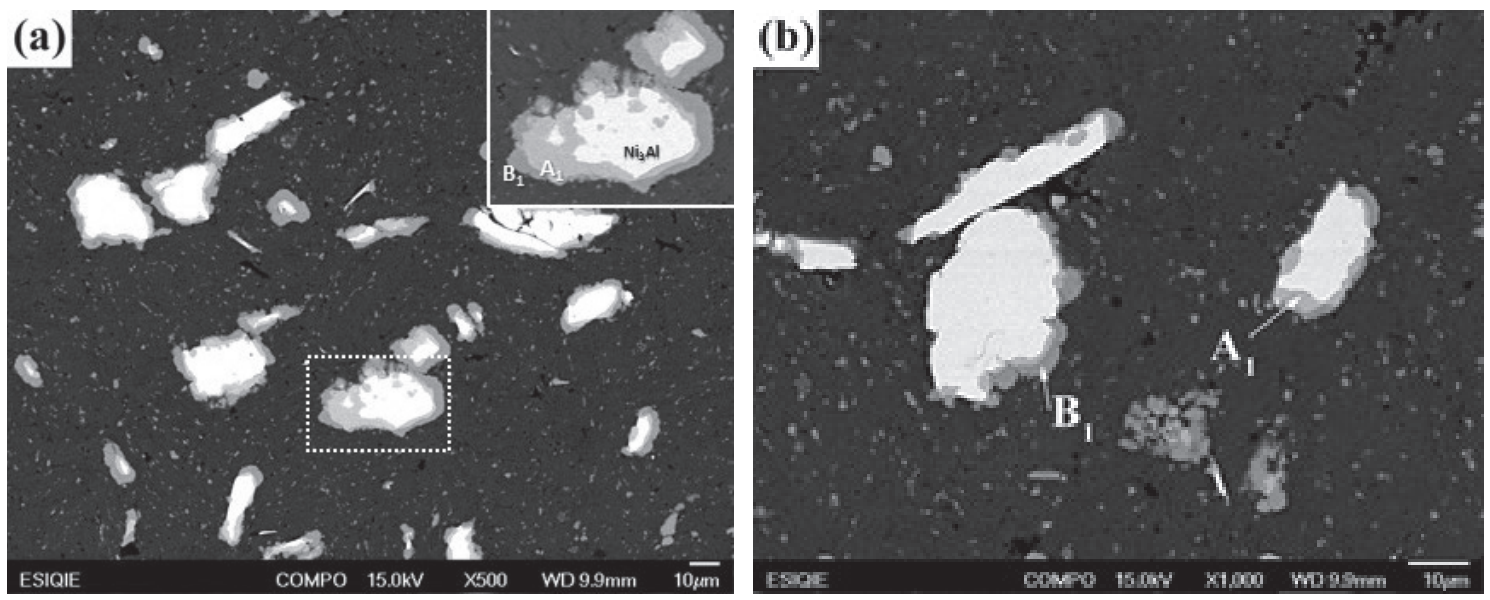

FIGURA 5. (a) Imágenes de electrones retrodispersados del compósito 4M47; (b) Regiones A1 y B1 seleccionadas para su análisis por EDS.
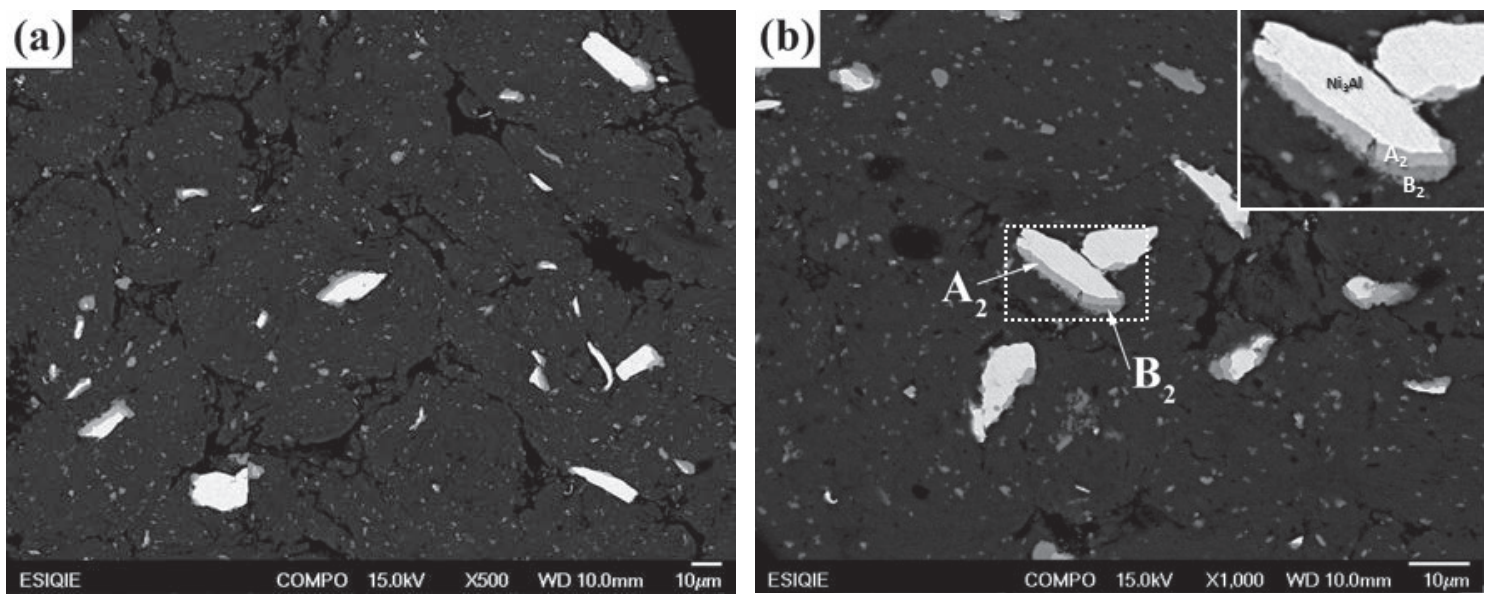

FiguRA 6. (a) Imágenes de electrones retrodispersados del compósito 5M16; (b) Regiones A1 y B1 seleccionadas para su análisis por EDS.

reforzantes de $\mathrm{Ni}_{3} \mathrm{Al}$ acelerando los procesos de difusión y propiciando la transformación de la fase de refuerzo en la interfaz. En la Fig. 6a se observa un mayor grado de porosidad debido a que la mala unión matriz-partícula, inhibió la difusión entre las partículas a pesar de que se empleó una mayor temperatura de consolidación $520^{\circ}$ y un mayor tiempo de permanencia $600 \mathrm{~s}$.

En las imágenes $5 \mathrm{a}$ y $6 \mathrm{a}$ se identifican partículas grandes de $142 \mu \mathrm{m}^{2}$ y $158,37 \mu \mathrm{m}^{2}$ en promedio, respectivamente en contraste claro embebidas en una matriz de contaste obscuro, así como partículas de menor tamaño $\left(1,2 \mu \mathrm{m}^{2}\right.$ en promedio) distribuidas uniformente en la matriz. Las partículas grandes en contraste claro se encuentran rodeadas de regiones color gris claro y obscuro producto de la reacción entre la matriz de Al y las partículas reforzantes de $\mathrm{Ni}_{3} \mathrm{Al}$ debido a las condiciones de sinterizado. El análisis por EDS de las regiones $\mathrm{A}_{1}, \mathrm{~A}_{2} \mathrm{y} \mathrm{B}_{1}, \mathrm{~B}_{2}$ de las Figs. $5 \mathrm{~b}$ y $6 \mathrm{~b}$ proporciona
Tabla 4. Composición Química de las regiones identificadas en las figuras 7(b) y 8(b) analizadas por EDS (at.\%)

\begin{tabular}{lcccc}
\hline Elementos & $\mathbf{A}_{\mathbf{1}}$ & $\mathbf{A}_{\mathbf{2}}$ & $\mathbf{B}_{\mathbf{1}}$ & $\mathbf{B}_{\mathbf{2}}$ \\
\hline $\mathrm{Al}$ & 61,43 & 62,48 & 76,8 & 75,58 \\
$\mathrm{Ni}$ & 38,57 & 37,52 & 23,2 & 24,42 \\
\hline
\end{tabular}

datos cuantitativos de la composición química de dichas regiones, los resultados se muestran en la Tabla 4. A partir de los resultados podemos establecer que la fase de la zona intermedia de color gris claro denominada A1 y A2 en las Figs. 5b y $6 \mathrm{~b}$ corresponde a la fase $\mathrm{Al}_{3} \mathrm{Ni}_{2}$ y la fase en color gris obscuro, denominada B1 y B2 en las Figs. 5b y 6 b, más externa es $\mathrm{Al}_{3} \mathrm{Ni}$ con el mayor contenido de Al. La descomposición de las partículas $\mathrm{Ni}_{3} \mathrm{Al}$ ocurre en la intercara con el $\mathrm{Al}$ por un proceso difusivo de $\mathrm{Ni}$ y $\mathrm{Al}$ formando las fases $\mathrm{Al}_{3} \mathrm{Ni}$ 
y $\mathrm{Al}_{3} \mathrm{Ni}_{2}$, ver regiones $\mathrm{B}$ y $\mathrm{A}$ en las Figs. $5 \mathrm{a}$ y $6 \mathrm{~b}$, respectivamente. Estos resultados son consistentes con los obtenidos del análisis de las muestras por DRX, que también indican la presencia de las fases intermetálicas $\mathrm{Al}_{3} \mathrm{Ni}_{2}$ y $\mathrm{Al}_{3} \mathrm{Ni}$.

\subsection{Análisis por nanoindentación}

En las Figs. 7 y 8 se presentan micrografías de las indentaciones realizadas en dos diferentes partículas de interés. Las indentaciones se realizaron en la fase identificada como $\mathrm{Ni}_{3} \mathrm{Al}$ y en la región exterior que corresponde a la fase $\mathrm{Al}_{3} \mathrm{Ni}$. Las Figs. 9a y 9 b muestran el promedio y barra de error de la dureza de las fases intermetálicas $\mathrm{Ni}_{3} \mathrm{Al}, \mathrm{Al}_{3} \mathrm{Ni}_{2}$, $\mathrm{Al}_{3} \mathrm{Ni}$ y de la matriz de $\mathrm{Al}$, en las condiciones de sinterizado 5M16 y 4M47, respectivamente. Si bien

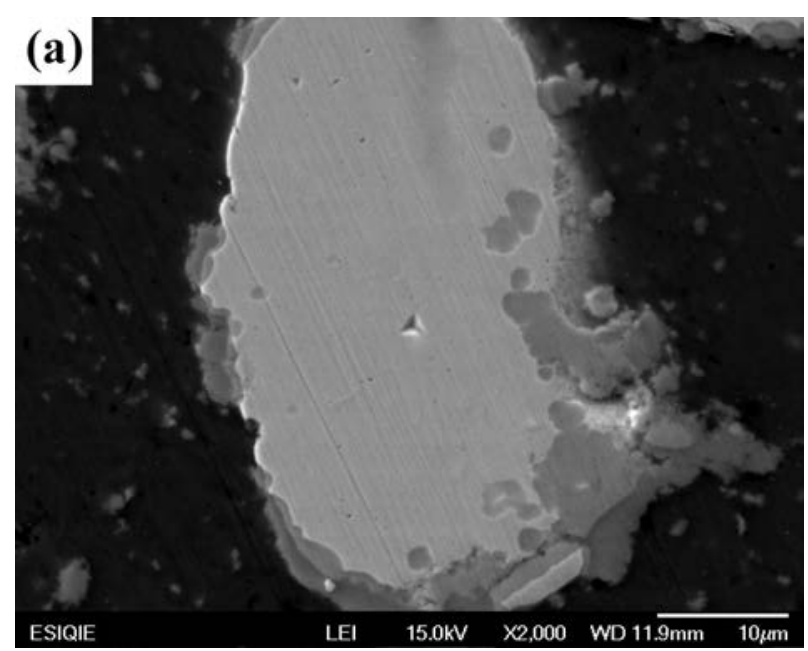

FIgURA 7. Micrografía de una nanoindentación en una partícula de Ni3Al.

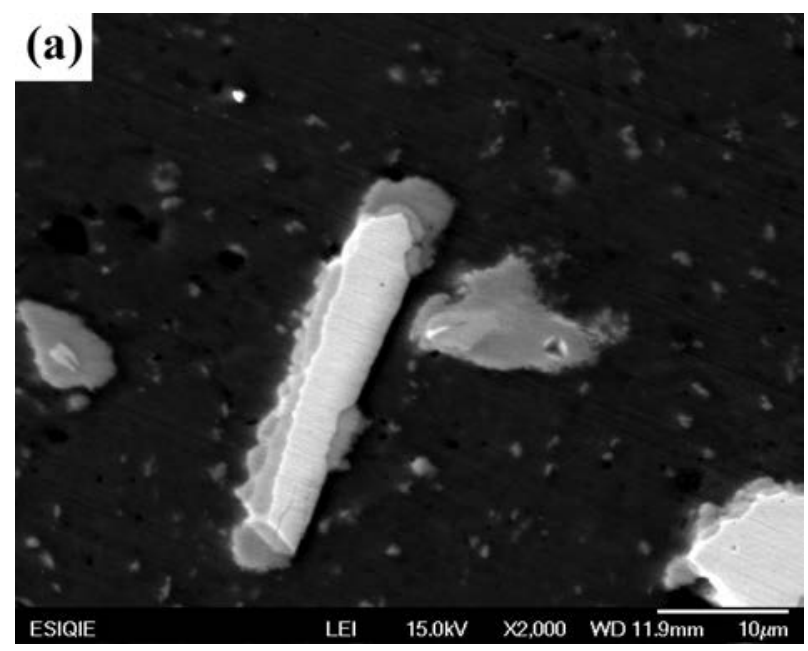

FIgURA 8. Micrografía de una nanoindentación en la región $\mathrm{Al}_{3} \mathrm{Ni}$. existe un traslapamiento de las barras de error entre ambas muestras, los valores promedio y los límites superiores de la condición 4M47 son ligeramente mayores que en la condición 5M16. Esto se atribuye a la mayor densificación obtenida en la condición 4M47. El mismo fenómeno es apreciable de manera más clara en las Figs. 10a y 10b que muestran el promedio del módulo de Young de las mismas fases. El método Oliver-Pharr (Oliver y Pharr, 2004) para el cálculo del módulo de Young se basa en la pendiente de la curva de descarga, que representa la rigidez al contacto del material. Un módulo de Young más elevado implica una mayor rigidez del material. Los valores más elevados de la condición 4M47 se pueden atribuir a la mejor consolidación debido a la presión de compactación, de manera similar a lo mencionado con los ensayos de microdureza Vickers.

En la Tabla 5 se presentan los valores de modulo elástico $\mathrm{E}$ y dureza $\mathrm{H}$ determinados por nanoindentación en este experimento, así como los citados en la literatura. Torralba et al. (2002) obtuvieron valores de dureza entre 11-12 GPa del intermetálico $\mathrm{Ni}_{3} \mathrm{Al}$ medido por nanoindentación, el cual esta embebido en una matriz de una aleación de aluminio AA 2014??. El compósito fue fabricado por $\mathrm{AM}$, extruido con una relación $25: 1,500{ }^{\circ} \mathrm{C}$, presión de $350 \mathrm{MPa}$, y sometido a un tratamiento T6 $\left(490{ }^{\circ} \mathrm{C}+160{ }^{\circ} \mathrm{C}\right.$ durante 18 h). Estos resultados son cercanos pero menores a los obtenidos en el presente trabajo empleando la técnica de SPS. Un factor que puede influenciar la dureza de las partículas es el efecto Hall-Petch. Si bien las partículas reforzantes son observables como aglomerados de varias micras cuadradas, la estructura de estas es nanocristalina como lo sugiere al análisis por MET. Por otro lado, el módulo de Young de la mayoría de los intermetálicos obtenidos es aparentemente menor a los reportados en otros trabajos (Eskin y Toropova, 1994; Zhang, 2004; Liming et al., 2010; Saheb et al., 2012). Esto es también atribuido a la policristalinidad de las partículas reforzantes. Estudios recientes sobre nanoindentación simulada (Seymour et al., 2014) han estimado que algunos intermetálicos presentan direcciones cristalográficas más suaves que otras, lo que podría estar impactando los valores de módulo elástico. Una manera de comprobar la naturaleza nanocristalina de las partículas reforzantes es mediante el análisis por MET.

La Fig. 11a muestra una micrografía del compósito 4M47 obtenida por MET empleando la técnica de campo claro en donde puede observarse partículas nanométricas de la fase $\mathrm{Ni}_{3} \mathrm{Al}$ que presentan una forma irregular con radio equivalente de hasta $10 \mathrm{~nm}$ dentro de la matriz de aluminio. El patrón de difracción de área selecta (SADP) mostrado en la Fig. 11b correspondiente a una partícula de $\mathrm{Ni}_{3} \mathrm{Al}$, sugiere un tamaño de cristal nanométrico en la estructura de 
(a)

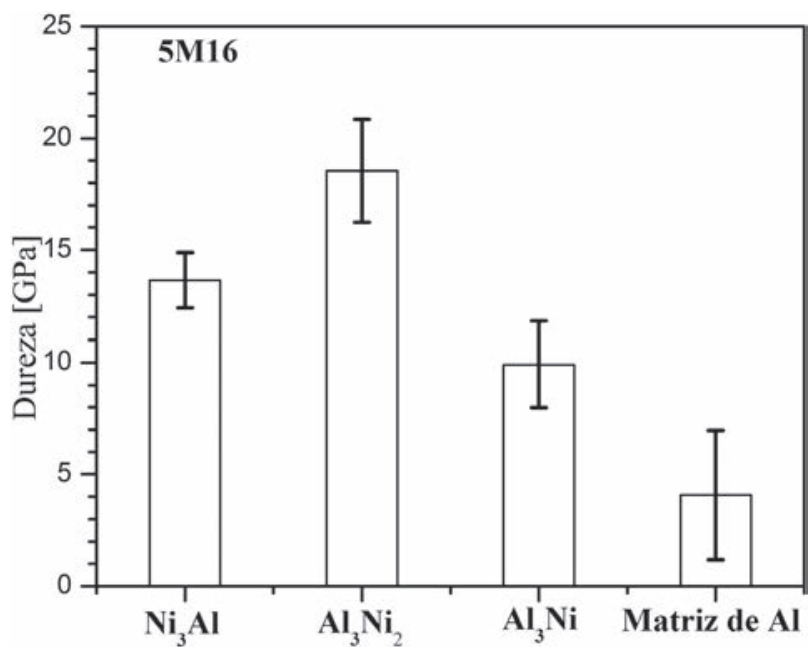

(b)

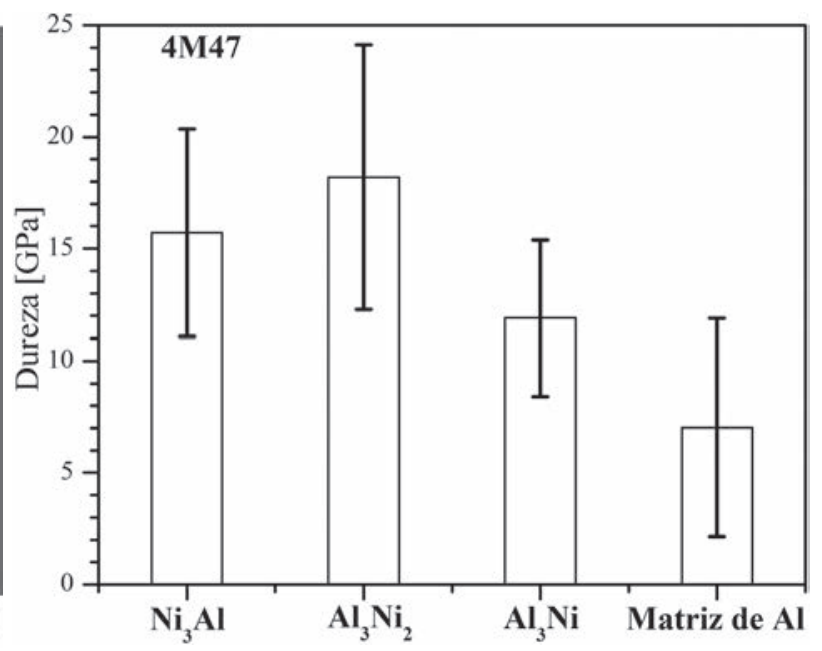

Figura 9. Valores de dureza de las fases interfaciales producidas en los compósitos: (a) 5M16 y (b) 4M47.

(a)

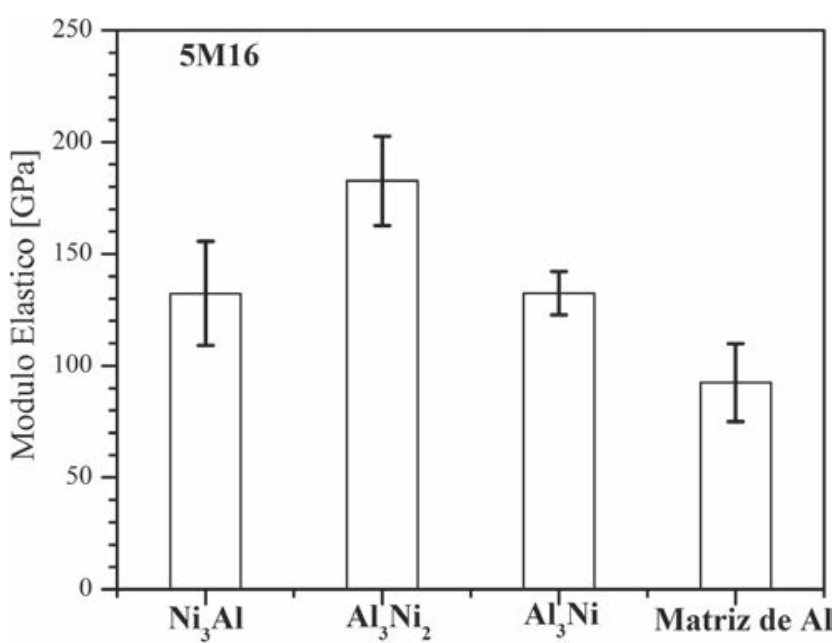

(b)

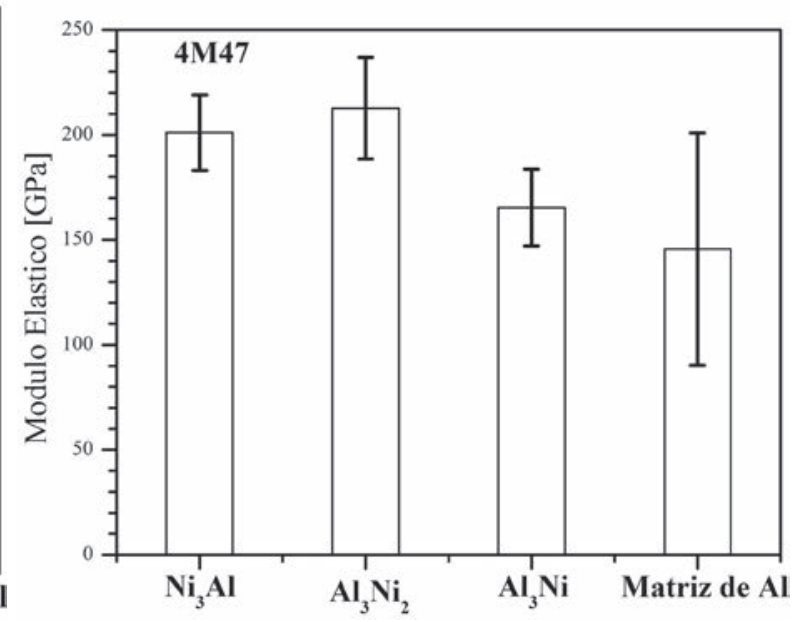

FIgURA 10. Valores de Modulo Elástico de las fases interfaciales producidas en los compósitos: (a) 5M16, y (b) 4M47.

Tabla 5. Comparación entre valores teóricos y experimentales de la dureza y módulo de elasticidad de las fases presentes en el compósito $\mathrm{Al} / \mathrm{Ni}_{3} \mathrm{Al}$ bajos las condiciones $4 \mathrm{M} 47$ y $5 \mathrm{M} 16$

\begin{tabular}{|c|c|c|c|c|c|c|}
\hline \multirow[b]{3}{*}{ Fase } & \multicolumn{2}{|c|}{ Otras investigaciones } & \multicolumn{4}{|c|}{ Resultados de esta Investigación } \\
\hline & \multirow[b]{2}{*}{ H (GPa) } & \multirow[b]{2}{*}{ E(GPa) } & \multicolumn{2}{|c|}{$4 \mathrm{M} 47$} & \multicolumn{2}{|c|}{$5 \mathrm{M} 16$} \\
\hline & & & H (GPa) & E (GPa) & H (GPa) & E (GPa) \\
\hline $\mathrm{Ni}_{3} \mathrm{Al}$ & $\begin{array}{c}9,5 \pm 0,6^{\mathrm{a}} \\
15^{\mathrm{d}} \\
9,88 \pm 0,3^{\mathrm{e}}\end{array}$ & $\begin{array}{c}218,5 \pm 7,8^{\mathrm{a}} \\
240^{\mathrm{d}} \\
261,98 \pm 8,9^{\mathrm{e}}\end{array}$ & $15,72 \pm 4,6$ & $201,07 \pm 18,0$ & $13,65 \pm 1,3$ & $132,32 \pm 23,3$ \\
\hline $\mathrm{Al}_{3} \mathrm{Ni}_{2}$ & $10,45 \pm 0,76^{\mathrm{b}}$ & $170,67 \pm 8,57^{\mathrm{b}}$ & $18,2 \pm 5,9$ & $212,72 \pm 24,2$ & $18,55 \pm 2,3$ & $182,66 \pm 20$ \\
\hline $\mathrm{Al}_{3} \mathrm{Ni}$ & $7,9^{\mathrm{c}}$ & $185,4^{\mathrm{c}}$ & $11,9 \pm 3,5$ & $165,37 \pm 18,2$ & $9,908 \pm 1,9$ & $132,46 \pm 9,6$ \\
\hline $\mathrm{Al}$ & & & 7,02 & 145,55 & 4,04 & 92,48 \\
\hline
\end{tabular}

${ }^{\mathrm{a}}$ Gan et al. (2012); ${ }^{\mathrm{b}}$ Chen et al. (2010); ${ }^{\mathrm{c}}$ Miranda et al. (2017); ${ }^{\mathrm{d}}$ Torralba et al. (2002) 

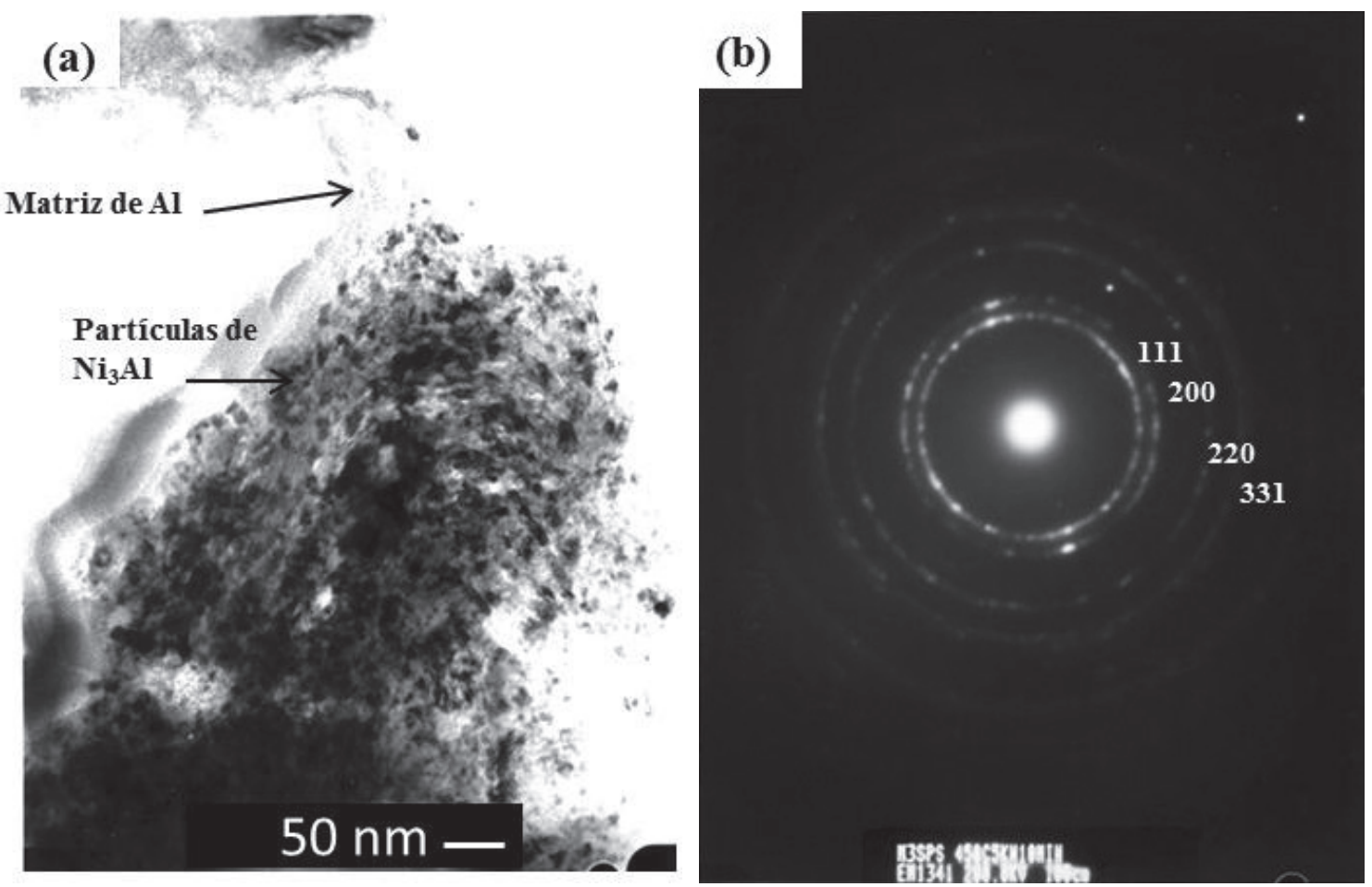

Figura 11. Micrografía de TEM del compósito 4M47: (a) Imagen de Campo Claro, y (b) Patrón de Difracción de Área Selecta de una partícula de Ni3Al.

(a)

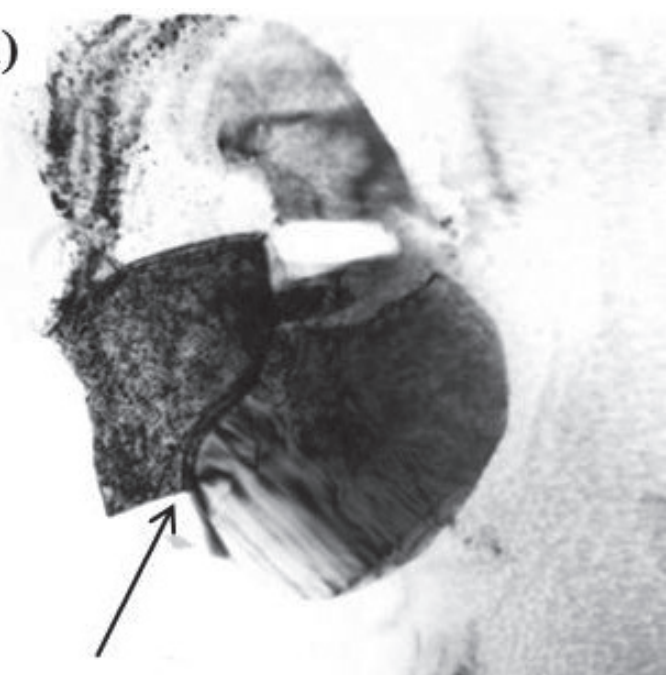

Matriz de Al

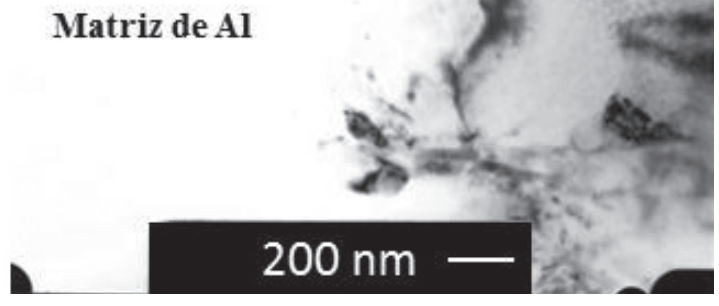

(b)

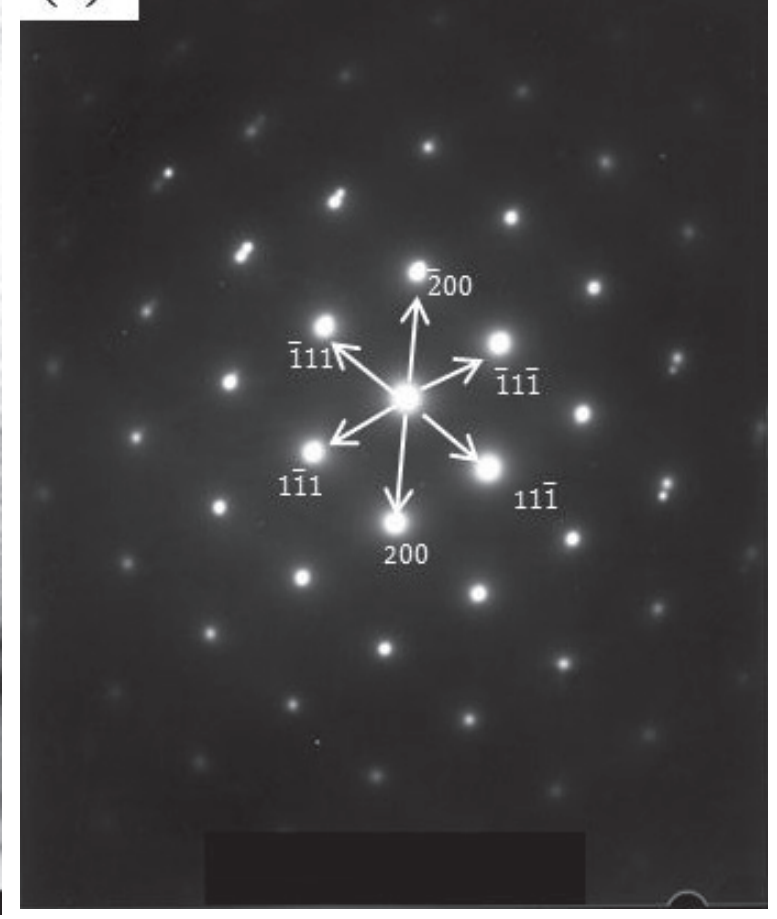

FIgURA 12. Micrografía de TEM del compósito 4M47: (a) Imagen de Campo Claro, y (b) Patrón de Difracción de Área Selecta de la matriz de Al. 
la partícula, soportada por los anillos de difracción bien definidos en la imagen. Estos resultados indican que la fase $\mathrm{Ni}_{3} \mathrm{Al}$ fue retenida durante el proceso de consolidación de los compósitos y conservo sus características nanométricas obtenidas por el proceso de AM. La imagen de campo claro mostrada en la Fig. 12a pertenece al compósito 4M47 y la indexación del patrón de difracción de area selecta (SADP) mostrado en la Fig. 12b indican que pertenece a la matriz de aluminio.

\section{CONCLUSIONES}

- La síntesis por SPS de compósitos base Al reforzados con $5 \%$ vol. de partículas de $\mathrm{Ni}_{3} \mathrm{Al}$ obtenidas por AM con características nanométricas presentaron altos valores de densidad $(>87 \%)$ debido a las condiciones de sinterizado. La mayor presión de compactación aplicada al compósito 4M47 condujo a elevar su densidad y dureza. Esto se atribuye a la presencia de las partículas intermetálicas reforzantes.

- El sinterizado por SPS conservó las características nanométricas de las partículas de $\mathrm{Ni}_{3} \mathrm{Al}$ debido a que la técnica permite reducir el tiempo de permanencia a alta temperatura la cual es la causa principal de crecimiento de grano. La microestructura del compósito 5M16 sinterizado por SPS a $520^{\circ} \mathrm{C}, 16 \mathrm{MPa}$ por $600 \mathrm{~s}$, indica que esta presión de sinterizado no es suficiente para reducir la porosidad a los niveles del compósito 4M47, a pesar de la mayor temperatura $\left(520{ }^{\circ} \mathrm{C}\right)$ empleada en sus síntesis. Ambos compósitos presentaron fases de reacción en la interfaz $\mathrm{Al}-\mathrm{Ni}_{3} \mathrm{Al}$ debido a las altas temperaturas de sinterización $\left(450^{\circ} \mathrm{C}\right.$ y $\left.520^{\circ} \mathrm{C}\right)$. Los valores de dureza y módulo elástico determinados por nanoindentación son mayores a los reportados en la literatura.

\section{AGRADECIMIENTOS}

Los autores agradecen al CONACYT y al IPNSIP-BEIFI por el apoyo económico.

\section{REFERENCIAS}

Abbasi, M., Azadbeh, M., Sajjadi, S. (2010). Evolution of manufacturing parameters in $\mathrm{Al} / \mathrm{Ni}_{3} \mathrm{Al}$ composite powder formation using blending and mechanical milling processes. J. Mater. Sci. 45 (16), 4524 4531. https://doi.org/10.1007/ s10853-010-4548-7.

Antolak-Dudka, A., Krasnowski, M., Kulik, M. (2013). Nanocrystalline $\mathrm{Ni}_{3} \mathrm{Al}$ produced by hot-pressing consolidation of mechanically alloyed powders. Intermetallics 42, 41-44. https://doi.org/10.1016/j.intermet.2013.05.014

Campo, M., Rams, J., Ureña, A. (2005). Determinación mediante nanoindentación de las propiedades mecánicas de la interfaz en materiales compuestos de aluminio reforzados con partículas de $\mathrm{SiC}$ recubiertas de sílice. Bol. Soc. Esp. Ceram. V. 44 (5), 270-277. https://doi.org/10.3989/ cyv.2005.v44.i5.347
Cao, G., Geng, L., Zheng, Z., Naka, M. (2007). The oxidation of nanocrystalline $\mathrm{Ni}_{3} \mathrm{Al}$ fabricated by mechanical alloying and spark plasma sintering. Intermetallics 15 (12), 1672-1677. https://doi.org/10.1016/j.intermet.2007.07.003.

Chen, C.-L., Richter, A., Thomson, R. (2009). Mechanical properties of intermetallic phases in multi-component Al-Si alloys using nanoindentation. Intermetallics 17 (8), 634-641. https://doi.org/10.1016/j.intermet.2009.02.003.

Díaz, C., González-Carrasco, J.L., Caruana, G., Lieblich, M. (1996). $\mathrm{Ni}_{3} \mathrm{Al}$ Intermetallic particles as wear-resistant reinforcement for Al-Base composites processed by powder metallurgy. Metall. Mater. Trans. A 27 (10), 3259-3266. https://doi.org/10.1007/BF02663876.

Enayati, M.H., Sadeghian, Z., Salehi, M., Saidi, A. (2004). The effect of milling parameters on the synthesis of $\mathrm{Ni}_{3} \mathrm{Al}$ intermetallic compound by mechanical alloying. Mat. Sci. Eng. A 375-377, 809-811. https://doi.org/10.1016/ j.msea.2003.10.060.

Eskin, Dm.G., Toropova, L.S. (1994). Tensile and elastic properties of deformed heterogeneous aluminum alloys at room and elevated temperatures. Mat. Sci. Eng. A 183 (1-2), L1-L4. https://doi.org/10.1016/0921-5093(94)90913-X.

Fang, Q., Kang, Z., Gan, Y., Long, Y. (2015). Microstructures and mechanical properties of spark plasma sintered $\mathrm{Cu}-\mathrm{Cr}$ composites prepared by mechanical milling and alloying. Mater. Design 88, 8-15. https://doi.org/10.1016/ j.matdes.2015.08.127.

Gan, B., Murakami, H., Maa, R., Meza, L., Greer, J., Ohmura, T., Tin, S. (2012). Nanoindentation and Nano-Compresion Testing of $\mathrm{Ni}_{3} \mathrm{Al}$ Precipitates. Superalloys 2012, 83-91. https://doi.org/10.1002/9781118516430.ch9.

Hernández, P., Dorantes Rosales, H., Hernández, F., Esquivel, R., Rivas, D., López, V. (2014). Synthesis and microstructural characterization of $\mathrm{Al}-\mathrm{Ni}_{3} \mathrm{Al}$ composites fabricated by press-sintering and shock-compaction. $A d v$. Powder Technol. 25 (1), 255-260. https://doi.org/10.1016/j. apt.2013.04.011.

Hungría, T., Galy, J., Castro, A. (2009). Spark Plasma Sintering as a Useful Technique to the Nanostructuration of PiezoFerroelectric Materials. Adv. Eng. Mater. 11 (8), 615-631. https://doi.org/10.1002/adem.200900052.

ICDD (2003). PDF-2/Inorganics 2003 (Database). Edited by Dr. Soorya Kabekkodu, International Centre for Diffraction Data, Newtown Square, PA, USA.

Li, X., Zhang, M., Zheng, D., Cao, T., Chen, J., Qu, S. (2015). The oxidation behavior of the WC- $10 \mathrm{wt} \% \mathrm{Ni}_{3} \mathrm{Al}$ composites fabricated by spark plasma sintering. J. Alloy Compd. 629, 148-154. https://doi.org/10.1016/j.jallcom.2015.01.010.

Lieblich, M., González-Carrasco, J., Caruana, G. (1997). Thermal stability of an $\mathrm{Al} / \mathrm{Ni}_{3} \mathrm{Al}$ composite processed by powder metallurgy. Intermetallics 5 (7), 515-524. https://doi. org/10.1016/S0966-9795(97)00027-7.

Liming, K., Huang, C., Xing, L., Huang, K. (2010). Al-Ni intermetallic composites produced in situ by friction stir processing. J. Alloy Compd. 503 (2), 494 499. https://doi. org/10.1016/j.jallcom.2010.05.040.

Meza, J.M., Franco, E.E., Farias, M.C.M., Buiochi, F., Souza, R.M., Cruz, J. (2008). Medición del módulo de elasticidad en materiales de ingeniería utilizando la técnica de nanoindentación instrumentada y de ultrasonido. Rev. Metal. 44 (1), 52-65. https://doi.org/10.3989/revmetalm.2008.v44. i1.95.

Miranda, G., Madeira, S., Silva, F.S., Carvalho, O. (2017). A nanoindentation study on $\mathrm{Al}_{3} \mathrm{Ni}$ interface of $\mathrm{Ni}$ reinforced aluminum-silicon composite. Mech. Adv. Mater. Struc. 24 (10), 871-874. https://doi.org/10.1080/15376494. 2016.1196790

Munir, Z.A., Anselmi-Tamburini, U., Ohyanagi, M. (2006). The effect of electric field and pressure on the synthesis and consolidation of materials: A review of the spark plasma sintering method. J. Mater. Sci. 41 (3), 763-777. https:// doi.org/10.1007/s10853-006-6555-2

Muñoz-Morris, M., Rexach, J., Lieblich, M. (2005). Comparative study of Al-TiAl composites with different intermetallic volume fractions and particle sizes. Intermetallics 13 (2) 141-149. https://doi.org/10.1016/j.intermet.2004.07.033. 
Mussert, K., Vellinga, W., Bakker , A., Van Der Zwagg, S. (2002). A nano-indentation study on the mechanical behaviour of the matrix material in an A AA60691$\mathrm{Al}_{2} \mathrm{O}_{3}$ MMC. J. Mater. Sci. 37 (4), 789-794. https://doi. org/10.1023/A:1013896032331.

O'Donnell, G., Looney, L. (2001). Production of aluminium matrix composite using conventional PM technology. Mat. Sci. Eng. A 303 (1-2), 292-301. https://doi.org/10.1016/ S0921-5093(00)01942-0.

Oliver, W., Pharr, G. (2004). Measurement of hardness and elastic modulus by instrumented indentation: Advances in understanding and refinements to methodology. J. Mater. Res. 19 (1), 3-20. https://doi.org/10.1557/jmr.2004.19.1.3.

Saheb, N., Iqbal, Z., Khalil, A., Saeed Hakeem, A., Al Aqeeli, N., Laoui, T., Kirchner, R. (2012). Spark Plasma Sintering of Metals and Metal Matrix Nanocomposites: A Review. J. Nanomater. 2012, ID 983470, 13 pages. https://doi. org/10.1155/2012/983470.

Saheb, N., Khan, M.S., Hakeem, A.S. (2015). Effect of Processing on Mechanically Alloyed and Spark Plasma Sintered Al- $\mathrm{Al}_{2} \mathrm{O}_{3}$ Nanocomposites. J. Nanomater. 2015, Article ID 609824, 13 pages. https://doi.org/10.1155/2015/609824

Sajjadi, S., Abbasi, M., Azadbeh, M. (2011). Evaluation of the Characteristics of Interfacial Phases Produced in $\mathrm{Al} / \mathrm{Ni}_{3} \mathrm{Al}$ Composite during Manufacturing. MSA 2 (9), 1340-1348. https://doi.org/10.4236/msa.2011.29182.

Sameezadeh, M., Emamy, M., Farhngi, H. (2016). Effect of MoSi distribution on room and high temperature mechanical properties of aluminum matrix composites. J. Mater. Res. 31 (12), 1741-1747. https://doi.org/10.1557/jmr.2016.190.

Seymour, R., Hemeryck, A., Nomura, K., Wang, W., Kalia, R.K., Nakano, A., Vashishta, P. (2014). Nanoindentation of $\mathrm{NiAl}$ and $\mathrm{Ni}_{3} \mathrm{Al}$ crystals on (100), (110), and (111) surfaces: A molecular dynamics study. Appl. Phys. Lett. 104 (14), 141904. https://doi.org/10.1063/1.4867168.

Suryanarayana, C., Norton, M. (1998). Determination of Crystallite Size and Lattice Strain. In X-ray Diffraction: A Practical Approach, Springer USA, pp. 207-221.
Torralba, J.M., Velasco, F., Costa, C.E., Vergara, I., Cáceres, D. (2002). Mechanical behavior of the interphase between matrix and reinforcement of Al 2014 matrix composites reinforced with $\left(\mathrm{Ni}_{3} \mathrm{Al}\right) \mathrm{p}$. Compos Part A Appl. Sci. Manuf. 33 (3), 427-434. https://doi. org/10.1016/S1359-835X(01)00104-X.

Torralba, J.M., Campos, M. (2014). Toward high performance in Powder Metallurgy. Rev. Metal. 50 (2), e017. https://doi. org/10.3989/revmetalm.017.

Torres, B., Lieblich, M., García-Escorial, A. (2006). Effect of heat treatments at $520{ }^{\circ} \mathrm{C}$ on aluminium alloy matrix composite reinforced with $\mathrm{Ni}_{3} \mathrm{Al}$ powder particles. Scripta Mater. 54 (8), 1485-1489. https://doi.org/10.1016/j.scriptamat. 2005.12.052.

Ureña, A., Rams, J., Campo, M., Sánchez, M. (2005). Aplicación de la nanoindentación para la determinación de las propiedades mecánicas interfaciales compuestos de matriz de aluminio. Rev. Metal. 41 (Vol. Extr.), 395-400. https://doi.org/10.3989/revmetalm.2005.v41. iExtra.1063.

Wang, Y., Rainforth, W.M., Jones, H., Lieblich, M. (2001). Dry wear behavior and its relation to microstructure of novel 6092 aluminium alloy- $\mathrm{Ni}_{3} \mathrm{Al}$ powder metallurgy composite. Wear 251 (1-2), 1421-1432. https://doi.org/10.1016/ S0043-1648(01)00783-9.

Xue, Y, Shen, R., Ni, S, Song, M., Xiao, D. (2015). Fabrication, microstructure and mechanical properties of $\mathrm{Al}-\mathrm{Fe}$ intermetallic particle reinforced Al-based composites. J. Alloys Compd. 618, 537-544. https://doi.org/10.1016/ j.jallcom.2014.09.009.

Yu, Y., Zhou, J., Chen, J., Zhou, H., Guo, C., Guo, B. (2010). Synthesis of nanocrystalline $\mathrm{Ni}_{3} \mathrm{Al}$ by mechanical alloying and its microstructural characterization. J. Alloys Compd. 498 (1), 107-112. https://doi.org/10.1016/j.jallcom. 2010.03.123

Zhang, D.L. (2004). Processing of advanced materials using high-energy mechanical milling. Prog. Mater. Sci. 49 (3-4), 537-560. https://doi.org/10.1016/S0079-6425(03)00034-3. 